\title{
Lake-inflows forecast using coupled water balance method and Xin'anjiang model in ungauged stream of Chaohu Lake Basin, China
}

\author{
Li zijun $^{1}$, Lei Xiaohui ${ }^{2}$, Liao Weihong ${ }^{2}$, Yang Qingchun ${ }^{1}$, Siyu Cai ${ }^{2}$, Wang Xiaoying ${ }^{3}$, Xie \\ Chuan $^{4}$, and Wang Jia ${ }^{5}$ \\ ${ }^{1}$ Jilin University \\ ${ }^{2}$ China Institute of Water Resources and Hydropower Research \\ ${ }^{3}$ Taiyuan University of Technology \\ ${ }^{4}$ Hebei Institute of hydrogeology and engineering geology \\ ${ }^{5}$ Sichuan University
}

July 9, 2020

\begin{abstract}
Water resources are crucial for maintaining daily life and healthy ecological environment. In order to gain a harmonious development among water resources and economic development in Chaohu Lake Watershed, it is urgent to quantify the lakeinflow. However, the accurate inflow forecast is severely limited by the lack of information regarding river flow (flow into Chaohu Lake). This paper attempts to overcome these problems through applying the integrated model, which coupled the water balance method and the Xin'anjiang model that the improved single objective particle swarm optimization was added. Meanwhile, the coupled model parameters were calibrated based on the objective function that the maximum weighted average Nash-Sutcliffe efficiency of the flood events with discontinuous time. In addition, the three copula functions (Clayton, Frank and Gumbel-Hougaard method) embodying bivariate probability distribution of annual precipitation and annual highest water level, were performed to select the typical year. According to the results of frequency analysis, Gumbel-Hougaard method is applied to select the typical hydrological years, including high inflow (2016), medium inflow (2007) and low inflow year (1978). Additionally, the calibration and verification results of the coupled model suggest that the simulation results are best in the high inflow year, followed by the media inflow year and the low inflow year. Also, annual lake inflow simulation in normal inflow year is $19.4 \times 108 \mathrm{~m} 3$, while the findings of the annual average land surface runoff of the study area is $18.9 \times 108 \mathrm{~m} 3$, indicating that the coupled water balance method and Xin'anjiang model have been proved to be robust in determining inflow in ungauged stream. The results of this present provides a basis for determining the appropriate operation and management of water resources systems.
\end{abstract}

\section{Hosted file}

Lake-inflows forecast using coupled water balance method and Xin'anjiang model in ungauged stream of Ch available at https://authorea.com/users/341360/articles/468294-lake-inflows-forecast-usingcoupled-water-balance-method-and-xin-anjiang-model-in-ungauged-stream-of-chaohu-lakebasin-china 

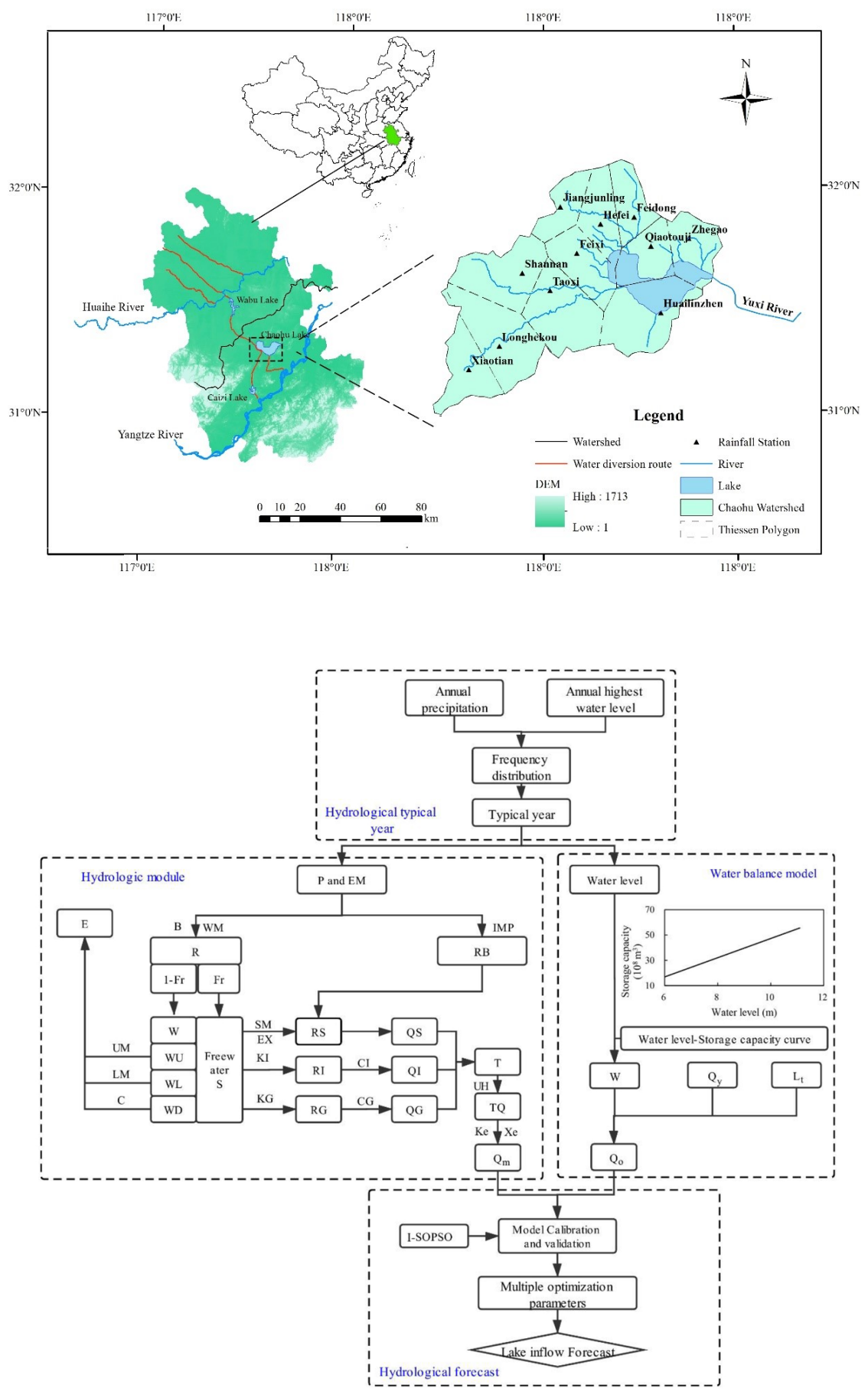

Note. Fr: contribution area; RB: runoff of impervious area; S: free water; QS: total surface runoff; QI: total interflow; QG: total groundwater runoff; Other parameter meanings can be seen in Table S1. 

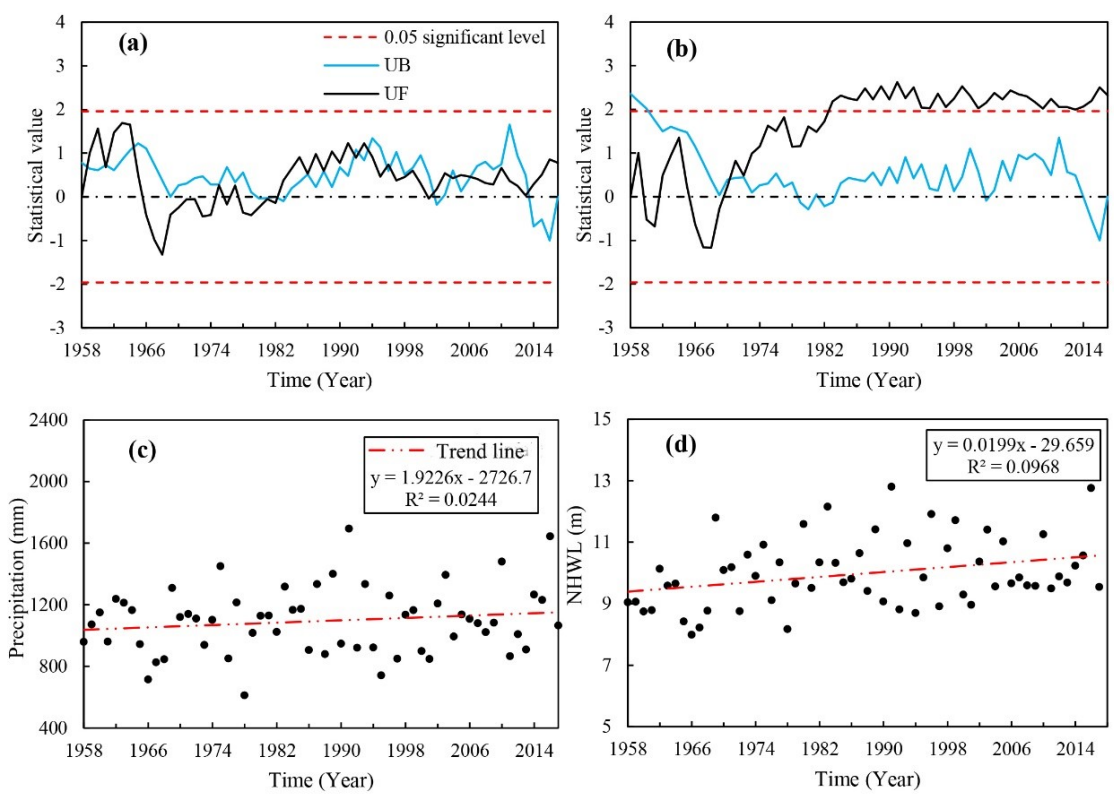

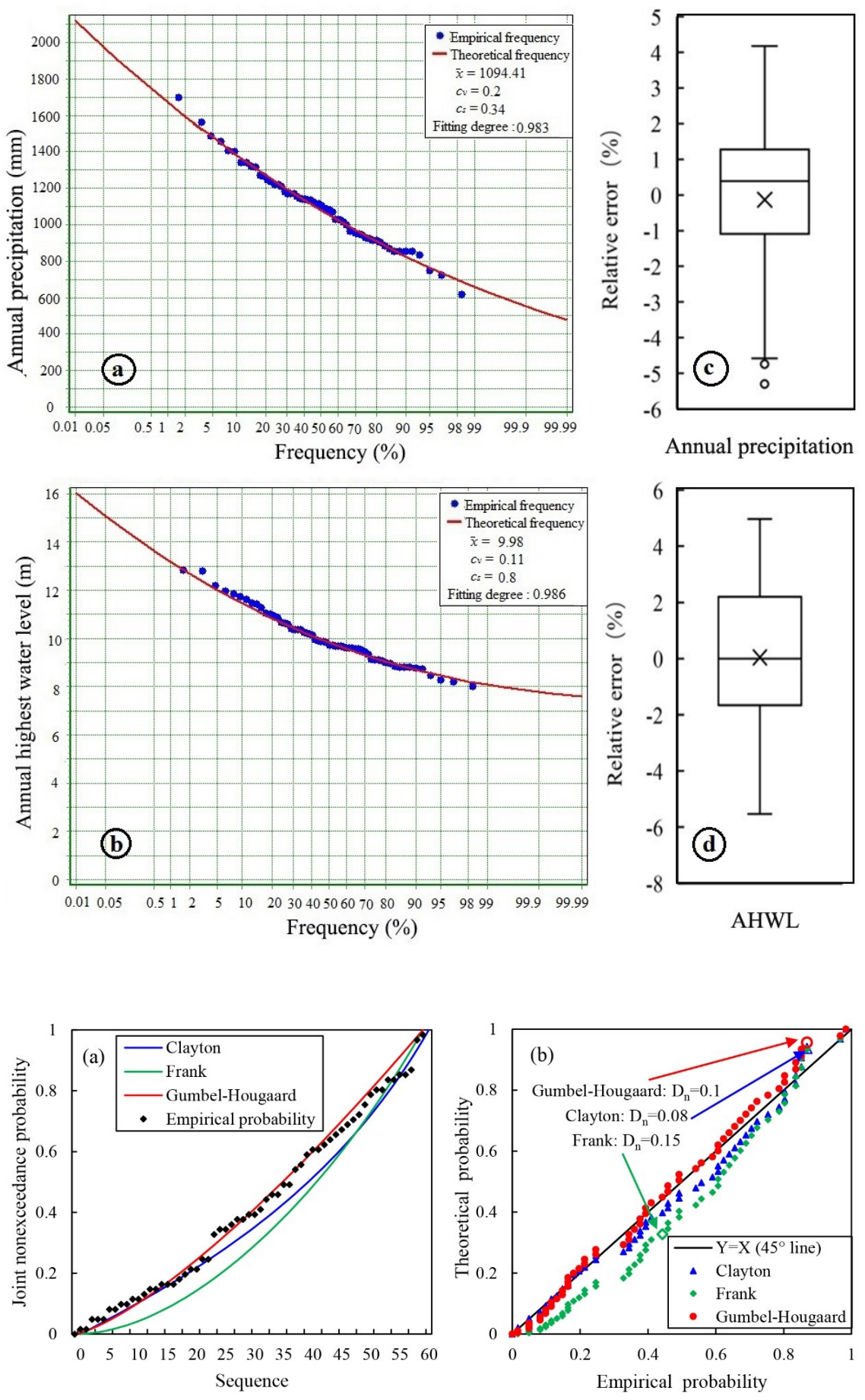

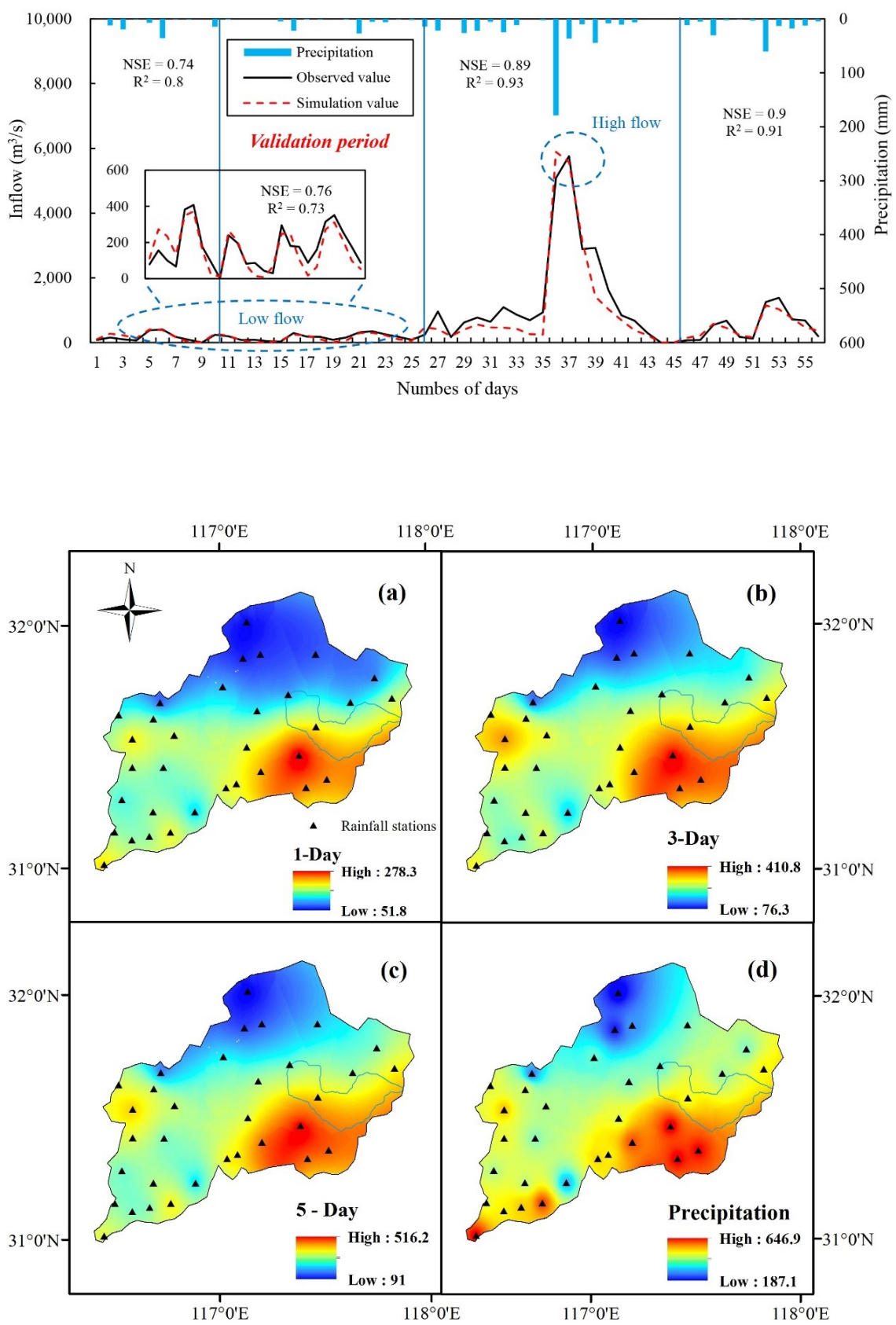


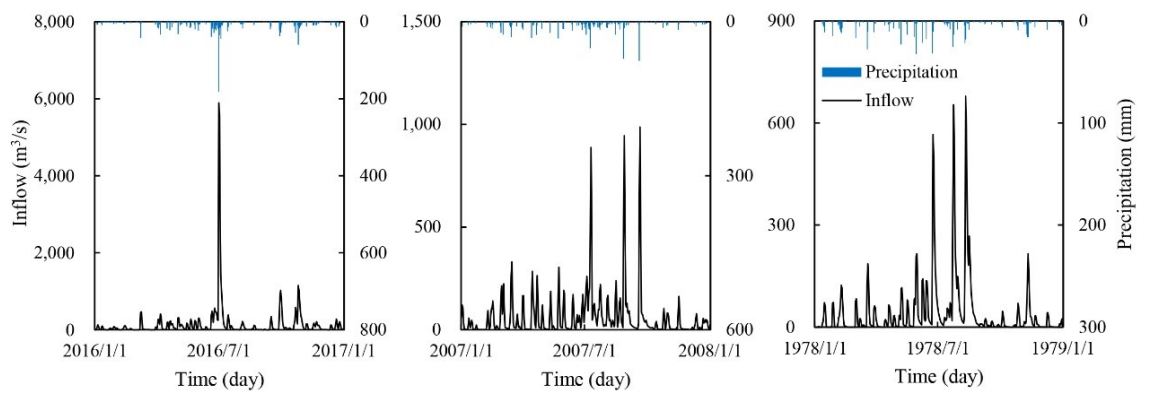

\section{Hosted file}

table1.docx available at https://authorea.com/users/341360/articles/468294-lake-inflowsforecast-using-coupled-water-balance-method-and-xin-anjiang-model-in-ungauged-stream-ofchaohu-lake-basin-china

\section{Hosted file}

table2.docx available at https://authorea.com/users/341360/articles/468294-lake-inflowsforecast-using-coupled-water-balance-method-and-xin-anjiang-model-in-ungauged-stream-ofchaohu-lake-basin-china

\section{Hosted file}

table3.docx available at https://authorea.com/users/341360/articles/468294-lake-inflowsforecast-using-coupled-water-balance-method-and-xin-anjiang-model-in-ungauged-stream-ofchaohu-lake-basin-china

\section{Hosted file}

table4.docx available at https://authorea.com/users/341360/articles/468294-lake-inflowsforecast-using-coupled-water-balance-method-and-xin-anjiang-model-in-ungauged-stream-ofchaohu-lake-basin-china 